\title{
Reduction Kinetics of the Nanocluster $\left[\mathrm{H}_{\mathrm{x}} \mathrm{PMo}_{12} \mathrm{O}_{40} \subset \mathrm{H}_{4} \mathrm{Mo}_{72} \mathrm{Fe}_{30}\left(\mathrm{O}_{2} \mathrm{CMe}\right)_{15} \mathrm{O}_{254}\left(\mathrm{H}_{2} \mathrm{O}\right)_{98-\mathrm{y}}(\mathrm{EtOH})_{\mathrm{y}}\right]$
}

\author{
Gibran L. Esquenazi ${ }^{1}$ Andrew R. Barron ${ }^{1,2,3}$ \\ Received: 2 August 2017 / Published online: 16 January 2018 \\ (C) The Author(s) 2018. This article is an open access publication
}

\begin{abstract}
The reduction of the molecular iron-molybdenum-nanocluster, $\left[\mathrm{H}_{\mathrm{x}} \mathrm{PMo}_{12} \mathrm{O}_{40} \subset \mathrm{H}_{4} \mathrm{Mo}_{72} \mathrm{Fe}_{30}\left(\mathrm{O}_{2} \mathrm{CMe}\right)_{15} \mathrm{O}_{254}\left(\mathrm{H}_{2} \mathrm{O}\right)_{98-\mathrm{y}}(\mathrm{EtOH})_{\mathrm{y}}\right]$ $(\mathrm{FeMoC})$, was studied using model free isoconversional methods. The reduction kinetics were evaluated using the nonisothermal thermogravimetric measurements at four different heating rates from 5 to $20{ }^{\circ} \mathrm{C} / \mathrm{min}$ in a $5 \%$ hydrogen atmosphere (argon balance). The apparent activation energy dependence on conversion derived from the isoconversional Kissinger-Akahira-Sunose (KAS) and Vyazovkin methods reveals a complex multi-step process with values ranging from $60.8 \pm 13.3$ to $183 \pm 6.3 \mathrm{~kJ} / \mathrm{mol}$. The kinetic results were validated by isothermal predictions. The results herein are useful for optimization and development of FeMoC derived Fe-Mo nanoalloy systems.
\end{abstract}

Keywords Reduction kinetics · Isoconversional model free method · Iron · Molybdenum · Nanocluster

\section{Introduction}

Nanostructured iron molybdenum alloys and their oxides exhibit desirable chemical, electrical, and mechanical properties showing promise for applications in gas sensing [1-4], energy storage [5-7], and catalysis [8-12]. Of particular interest, are Fe-Mo nanoalloys used for catalytic chemical vapor deposition of carbon nanotubes (CNTs). The $\mathrm{Fe}-\mathrm{Mo}$ catalyst system has proven itself to be excellent for CNT growth with reports demonstrating; ultra-long aligned CNT growth $(>18.5 \mathrm{~cm})$ [13], large area and ultra-highdensity CNT growth (160 SWCNTs $\left./ \mu \mathrm{m}^{2}\right)$ [14], and CNT growth under a wide range of temperatures $\left(450-1000{ }^{\circ} \mathrm{C}\right)$ [15-17]. Preparation of Fe-Mo nanoalloys has been demonstrated by several chemical and physical methods,

Electronic supplementary material The online version of this article (https://doi.org/10.1007/s10876-018-1335-0) contains supplementary material, which is available to authorized users.

Andrew R. Barron

arb@rice.edu

1 Department of Chemistry, Rice University, Houston, TX 77005, USA

2 Department of Materials Science and Nanoengineering, Rice University, Houston, TX 77005, USA

3 Energy Research Safety Institute (ESRI), Swansea University, Bay Campus, Swansea, SA1 8EN Wales, UK including thermal decomposition [18], solution phase wet chemical reduction [19], electrochemical synthesis [20], microwave synthesis [21], sono-chemical synthesis [22], chemical vapor condensation [23], and high-energy ball milling [24]. However precise size and stoichiometric control of nanoalloys remains a challenge. Our prior work with $\left[\mathrm{H}_{\mathrm{x}} \mathrm{PMo}_{12} \mathrm{O}_{40} \subset \mathrm{H}_{4} \mathrm{Mo}_{72} \mathrm{Fe}_{30}\left(\mathrm{O}_{2} \mathrm{CMe}\right)_{15} \mathrm{O}_{254}\left(\mathrm{H}_{2} \mathrm{O}\right)_{98-\mathrm{y}}(\mathrm{EtOH})_{\mathrm{y}}\right]$ (abbreviated as 'FeMoC' for 'iron-molybdenum cluster') demonstrated the critical importance of the reduction step in the "activation" of $\mathrm{FeMoC}$ as a catalyst for carbon nanotubes [25]. FeMoC is a large molecular cluster with uniform size $(\sim 2.5 \mathrm{~nm})$ and composition $\left(\mathrm{Fe}_{30} \mathrm{Mo}_{84} \mathrm{O}_{324}\right)$, that is readily functionalized [26, 27], and can be used for preparation of Fe-Mo nanoalloys by gas-solid reduction $[25,28]$. Prompted by the desire to better understand the reduction process to maximize the catalytic activity of the $\mathrm{Fe}-\mathrm{Mo}$ nanoparticles, and a desire for a predictive tool for $\mathrm{FeMoC}$ reduction, kinetic studies were undertaken. The results of this study are presented herein.

\section{Materials and Methods}

\section{Materials}

Chemicals for the synthesis of FeMoC (phosphomolybdic acid hydrate, iron(II) chloride tetrahydrate, sodium 
molybdate dihydrate, and 200 proof EtOH) were purchased from Sigma-Aldrich and used as received. The 5\% hydrogen gas (Ar balance) was obtained from BOC gases (gravimetrically certified).

\section{Synthesis}

The molecular nanocluster FeMoC $\left[\mathrm{H}_{\mathrm{x}} \mathrm{PMo}_{12} \mathrm{O}_{40} \subset \mathrm{H}_{4}\right.$ $\left.\mathrm{Mo}_{72} \mathrm{Fe}_{30}\left(\mathrm{O}_{2} \mathrm{CMe}\right)_{15} \mathrm{O}_{254}\left(\mathrm{H}_{2} \mathrm{O}\right)_{98-\mathrm{y}}(\mathrm{EtOH})_{\mathrm{y}}\right]$ was synthesized, purified, and characterized as previously reported $[25,28]$. Briefly, iron(II) chloride tetrahydrate $(1.00 \mathrm{~g}$, $5.03 \mathrm{mmol}$ ) was dissolved in $75 \mathrm{~mL}$ of Millipore water followed by the addition of sodium molybdate dihydrate $(2.00 \mathrm{~g}, 8.27 \mathrm{mmol})$. To this solution, pure glacial acetic acid $(10 \mathrm{~mL}, 59 \mathrm{mmol})$ and phosphomolybdic acid hydrate $(2.50 \mathrm{~g}, 1.37 \mathrm{mmol})$ was added. The solution $\mathrm{pH}$ was then adjusted to 2 with $\mathrm{HCl}$ and stirred at room temperature for $45 \mathrm{~min}$. Afterwards, the solution was filtered through a fine glass frit. The filtrate was then left in air to crystallize. The crystals were then vacuum filtered, washed with cold $\mathrm{H}_{2} \mathrm{O}$, and dried. The solid was transferred to a filter thimble and placed inside a Soxhlet extractor. EtOH was refluxed in the extractor for at least $12 \mathrm{~h}$ and a dark green solution was collected.

Characterization of the product from the green solution was carried out by UV-visible spectroscopy, transmission electron microscopy (TEM), Raman spectroscopy, and Fourier transform infrared spectroscopy (FT-IR). All characterization techniques show the materials to be identical to previously reported FeMoC samples [25, 28-31]. TEM was performed using a JEOL 1230 high contrast transmission electron microscope at $120 \mathrm{kV}$ equipped with a CCD camera. TEM samples were prepared by drop-casting a dilute FeMoC solution in EtOH $(0.1 \mu \mathrm{M})$ onto 400 -mesh lacey carbon TEM grids (Ted Pella, Inc., Product No. 01824). The ultraviolet-visible (UV-visible) spectrum was collected on an Agilent 8453 UV-visible spectroscopy system in EtOH solution. Fourier transform infrared (FT-IR) spectroscopy was obtained using a Nicolet iS50 FT-IR Infrared Microscope with an ATR objective with $2 \mathrm{~cm}^{-1}$ resolution. Raman spectroscopy was collected using a Renishaw inVia Raman Microscope. Measurements were performed using a $514.5 \mathrm{~nm}$ wavelength laser, with a $50 \times$ LWD lens, and cosmic-ray background removal applied.

\section{Experimental Techniques}

TGA experiments were performed on a TA instruments Q-600 using a carrier gas of 5\% hydrogen with an argon balance. The 5\% hydrogen gas blend was chosen because it was the carrier gas used in our prior work with $\mathrm{FeMoC}$ as a carbon nanotube catalyst [25]. In addition, the same gas concentration has been previously employed in studies of the reduction of both iron oxide and molybdenum oxide [32-36], thus allowing for a direct comparison of the results. FeMoC samples were prepared by evaporating $1 \mathrm{~mL}$ of a concentrated FeMoC-EtOH solution resulting in $\sim 20 \mathrm{mg}$ samples. The samples were then placed in alumina pans and heated with a linear ramp rate $(5,10,15$, and $20{ }^{\circ} \mathrm{C} / \mathrm{min}$ ) under a carrier gas flow of $70 \mathrm{~mL} / \mathrm{min}$. In addition to the multiple non-isothermal experiments an isothermal experiment at $850{ }^{\circ} \mathrm{C}$ was performed to validate the kinetic analysis. Here a $\sim 20 \mathrm{mg}$ sample of FeMoC was first heated to $500{ }^{\circ} \mathrm{C}$ under a $70 \mathrm{~mL} / \mathrm{min}$ flow of $5 \%$ hydrogen (Ar balance) to prevent misinterpretation by sublimed high oxidation state species in the kinetic analysis. At $500{ }^{\circ} \mathrm{C}$, the carrier gas was switched to pure argon $(70 \mathrm{~mL} / \mathrm{min}$ ) and the $\mathrm{FeMoC}$ sample was then heated to the isothermal temperature of 850 at a $60{ }^{\circ} \mathrm{C} / \mathrm{min}$ heating rate. Once stabilized at $850{ }^{\circ} \mathrm{C}$, the carrier gas was switched back to a $70 \mathrm{~mL} / \mathrm{min}$ flow of $5 \%$ hydrogen (Ar balance) and kept constant during the isothermal experiment for $6 \mathrm{~h}$. For all experiments, the simultaneous thermogravimetric/ differential scanning calorimetry (TGA/DSC) measurements were recorded. Scanning electron microscopy (SEM) measurements were performed on a FEI Quanta 400 by placing samples onto fixed aluminum SEM stubs. Images were acquired at an operating voltage of $30 \mathrm{kV}$, with a working distance of $10 \mathrm{~mm}$, and spot size of 3 .

\section{Kinetic Fundamentals and Background}

The fundamental equation to study the kinetics of thermally stimulated reactions can be described in terms of the reaction rate constant and reaction model, Eq. (1), where, $\alpha$ is conversion, $t$ is time, $T$ is temperature, $K(T)$ is the rate constant and $f(\alpha)$ is the reaction model.

$\frac{d \alpha}{d t}=\mathrm{K}(\mathrm{T}) f(\alpha)$

The value of conversion, $\alpha$, typically describes the overall progress of reactants to products. This overall progress may consist of more than one single reaction or proceed via multiple steps, of which each step has its specific extent of conversion. The degree of conversion, $\alpha$, is calculated from the weight loss of the hydrogen reduction experiments as follows in Eq. (2), where $m_{0}$ is the initial sample weight, $\mathrm{m}_{\mathrm{t}}$ is the weight of the sample at time, $t$, and $\mathrm{m}_{\propto}$ is the final sample weight.

$\alpha=\frac{m_{0}-m_{t}}{m_{0}-m_{\infty}}$

The rate constant, $\mathrm{K}(\mathrm{T})$, is expressed here as Eq. (3), where, $\mathrm{A}$ is the pre-exponential factor, $\mathrm{E}_{\mathrm{a}}$ is the apparent activation energy, and $\mathrm{R}$ is the gas constant. 


$$
\mathrm{K}(\mathrm{T})=\mathrm{A} e^{-E_{a} / R T}
$$

For non-isothermal data analysis with a constant heating rate program the heating rate term, $\beta$, is applied resulting in Eq. (4), where, $\beta=\mathrm{dT} / \mathrm{dt}$.

$\frac{d \alpha}{d T}=\frac{A}{\beta} e^{-E_{a} / R T} f(\alpha)$

The integral form of Eq. (4) used here for kinetic analysis is expressed as Eq. (5), where $x=E_{a} / R T$, and the $p(x)$ function is the temperature integral [37].

$g(\alpha)=\frac{A}{\beta} \int_{0}^{T} \exp \left(\frac{-E_{a}}{R T}\right) d T=\frac{A E_{a}}{\beta R} p(x)$

The temperature integral has no analytical solution, but can be solved using numerous approximation functions or by numerical integration.

\section{Isoconversional Analysis Methods}

The isoconversional principle states that the reaction rate at constant extent of conversion is only a function of temperature. This is demonstrated by taking the logarithmic derivative of the reaction rate (Eq. 1) at a constant conversion, $\alpha$, resulting in Eq. (6).

$$
\left[\frac{\partial \ln (d \alpha / d t)}{\partial T^{-1}}\right]_{\alpha}=\left[\frac{\partial \ln K(T)}{\partial T^{-1}}\right]_{\alpha}+\left[\frac{\partial \ln f(\alpha)}{\partial T^{-1}}\right]_{\alpha}
$$

Since at constant conversion, $\alpha$, the reaction model, $f(\alpha)$, is also constant, thus the second term in Eq. (6) is zero, resulting in Eq. (7) [38], where $\mathrm{E}_{\alpha}$ is the apparent activation energy for a specific extent of conversion, $\alpha$.

$\left[\frac{\partial \ln (d \alpha / d t)}{\partial T^{-1}}\right]_{\alpha}=-\frac{E_{\alpha}}{R}$

The isoconversional method uses data from multiple heating rates to describe the kinetics of thermally stimulated processes by using multiple single-step kinetic equations, each step associated with a specific extent of conversion [39]. This allows for the detection of complex multi-step processes by evaluating $\mathrm{E}_{\alpha}$ dependence on conversion, $\alpha$.

\section{Kissinger-Akahira-Sunose Method}

The Kissinger-Akahira-Sunose (KAS) isoconversional method is based on Eq. (8) [40, 41].

$\ln \left(\frac{\beta}{T^{2}}\right)=\ln \left(\frac{A R}{E_{\alpha} g(\alpha)}\right)-\frac{E_{\alpha}}{R T}$
Here the apparent activation energy for different values of conversion are derived from the linear slope of the $\ln \left(\beta / \mathrm{T}^{2}\right)$ versus $1 / T$ plot using multiple heating rates.

\section{Vyazovkin Method}

The isoconversional Vyazovkin method utilizes numerical integration instead of approximations of the temperature integral. The apparent activation energy, $E_{\alpha}$, for each conversion value, $\alpha$, can be determined by minimizing the $\Phi\left(\mathrm{E}_{\alpha}\right)$ function in Eq. (9) [42], where $I\left(\mathrm{E}_{\alpha}, \mathrm{T}_{\alpha, \mathrm{i}}\right)$ is defined in Eq. (10), where $i$ and $j$ denote independent experimental runs performed at different heating rates.

$\emptyset\left(\mathrm{E}_{\alpha}\right)=\sum_{i=1}^{n} \sum_{j \neq 1}^{n} \frac{I\left(\mathrm{E}_{\alpha}, T_{\alpha, i}\right) \beta_{j}}{I\left(\mathrm{E}_{\alpha}, T_{\alpha, i}\right) \beta_{i}}=\min$

$I\left(\mathrm{E}_{\alpha}, T_{\alpha, i}\right)=\int_{0}^{T_{\alpha}} \exp \left(\frac{-E_{\alpha}}{R T}\right) d T$

Here an Excel Macro was used to compute the value of $E_{\alpha}$ that minimizes the $\Phi\left(\mathrm{E}_{\alpha}\right)$ function. The experimental values of $T$ and $\beta$ are substituted in Eq. (9) with varying $E_{\alpha}$ values to identify the minimum $\Phi\left(\mathrm{E}_{\alpha}\right)$ function value that identifies the apparent activation energy at a given conversion. In Excel, the temperature integral (Eq. 10) values were evaluated numerically by utilizing the trapezoidal rule with uniform grid spacing, that is decreased, until the integral value difference is smaller than $10^{-6}$ between consecutive interactions [43]. The procedure for minimizing the $\Phi\left(E_{\alpha}\right)$ function is repeated for each conversion value (conversion step size, $\Delta \alpha=0.05$ ) to obtain the dependence of the apparent activation energy on the extent of conversion.

\section{Results and Discussion}

\section{FeMoC Synthesis and Characterization}

The molecular nanocluster $\left[\mathrm{H}_{\mathrm{x}} \mathrm{PMo}_{12} \mathrm{O}_{40} \subset \mathrm{H}_{4} \mathrm{Mo}_{72} \mathrm{Fe}_{30}\right.$ $\left.\left(\mathrm{O}_{2} \mathrm{CMe}\right)_{15} \mathrm{O}_{254}\left(\mathrm{H}_{2} \mathrm{O}\right)_{98-\mathrm{y}}(\mathrm{EtOH})_{\mathrm{y}}\right](\mathrm{FeMoC})$ was synthesized, purified, and characterized as previously reported [28]. The nanoparticulate nature of $\mathrm{FeMoC}$ was confirmed using TEM. Figure 1 shows a typical TEM image, which reveals spherical nanoparticles of ca. $2.5 \mathrm{~nm}$ in diameter characteristic of FeMoC [29]. The UV-visible spectrum of the as prepared material is shown in Fig. 2, and shows bands at 548, 880, and $1045 \mathrm{~nm}$ corresponding to the characteristic features of FeMoC [25, 28, 29]. The bands are associated with the nucleus shell charge transfer between Keggin guest and host $(550 \mathrm{~nm})$ and the $[\mathrm{Mo}(\mathrm{V}) \rightarrow \mathrm{Mo}(\mathrm{VI})]$ charge transfer in the Keggin cluster 


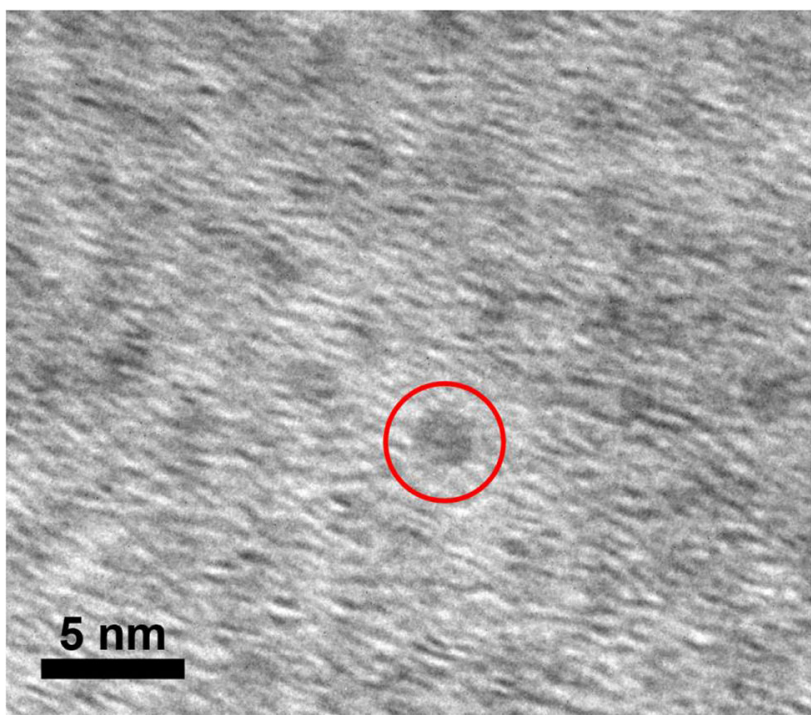

Fig. 1 The TEM image of the synthesized product diluted in EtOH showing the presence of ca. $2.5 \mathrm{~nm}$ diameter particles characteristic of FeMoC (circled)

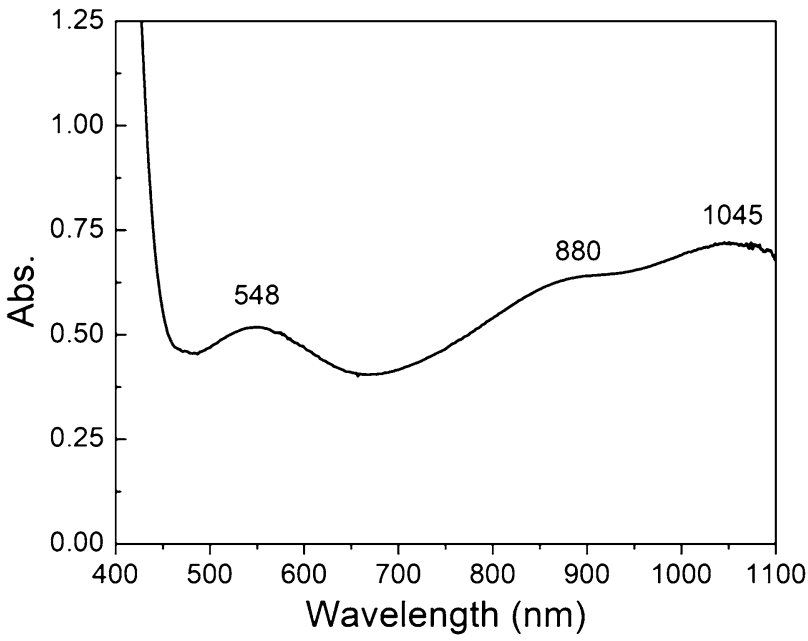

Fig. 2 The UV-visible spectra of a concentrated solution of the synthesized product (see experimental) diluted in ethanol

(880 and $1045 \mathrm{~nm}$ ) [29]. The FT-IR and Raman spectra of the synthesized product (Figs. 3 and 4, respectively) show the characteristic features of $\mathrm{FeMoC}$ (Tables 1 and 2, respectively) [28-31]. The FT-IR peaks at 1267, 2921, and $2971 \mathrm{~cm}^{-1}$ (Fig. 3, peaks 5, 9, and 10) and Raman spectra peak at $830 \mathrm{~cm}^{-1}$ (Fig. 4, peak 3) are indicative of the FeMoC structure [28, 29].

\section{FeMoC Reduction}

The reduction of iron-molybdenum oxides has been previously studied; however, the literature reports varied

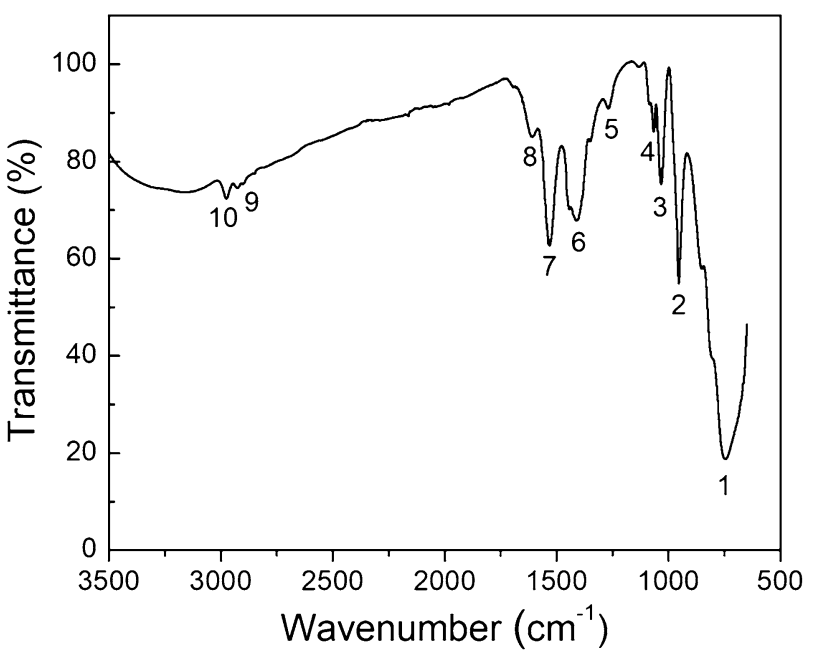

Fig. 3 The FT-IR spectra of the synthesized product. See Table 1 for peak numbering and assignment

kinetic results, indicating the importance of analysis methods and experimental conditions [44-48]. Table 3 shows the apparent activation energies $\left(E_{a}\right)$ reported in literature with the corresponding temperature range, experimental conditions, kinetic analysis methods, and proposed reaction mechanisms.

In this study, we use a non-isothermal isoconversional method to evaluate the FeMoC reduction kinetics by thermogravimetric analysis (TGA). The non-isothermal technique was chosen to avoid the disadvantages of the isothermal technique. Mainly, the limited temperature range of useful kinetic data i.e., at low isothermal temperatures experiments may not reach complete conversion. And conversely at a high temperatures, the warm-up time prior to the isothermal regime may result in samples undergoing a non negligible weight loss, complicating the kinetic data interpretation and deduction [50]. This is important to note given the volatility of molybdenum oxide and $\mathrm{FeMoC}$, the later beginning to volatilize at temperatures as low as $650{ }^{\circ} \mathrm{C}$ [25], and the former demonstrating pronounced sublimation at $\mathrm{T}>\sim 700{ }^{\circ} \mathrm{C}$ [51]. The "model free" isoconversional methods were used to avoid the required assumptions found in "model fitting" approaches. In model fitting methods, assumed hypothetical reaction models (Table 4) are forcibly fitted to the experimental data resulting in almost any assumed reaction model satisfactorily fitting at the expense of drastic variations in the Arrhenius parameters [52]. Consequently, model fitting approaches may fail to provide meaningful kinetic results, given their potential for dubious Arrhenius values. In contrast, model free approaches circumvent the necessity for reaction model assumptions, yielding kinetic parameters as function of either conversion (isoconversional analysis) or temperature (non-parametric kinetics) 
Fig. 4 The Raman spectrum $(514.5 \mathrm{~nm})$ of the synthesized product. See Table 2 for peak numbering and assignment
Table 1 The FT-IR peak assignment for the synthesized product

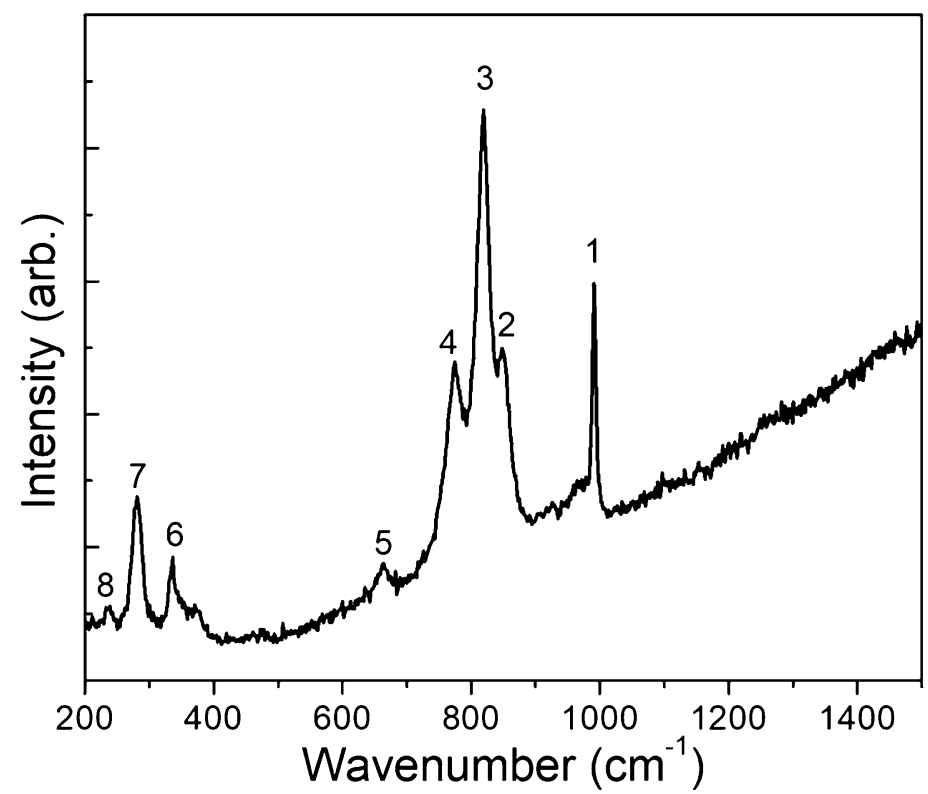

\begin{tabular}{llll}
\hline Peak $^{\mathrm{a}}$ & Wavenumber $\left(\mathrm{cm}^{-1}\right)$ & Assignment & References \\
\hline 1 & 755 & Keplerate, $\mathrm{s}$ & {$[31]$} \\
2 & 954 & Keplerate, $\mathrm{v}\left(\mathrm{MoO}_{\mathrm{t}}\right)$ & {$[29]$} \\
3 & 1035 & Keggin, $\mathrm{P}-\mathrm{OH}$ shift & {$[28]$} \\
4 & 1066 & Keggin, w, $\mathrm{v}_{\mathrm{as}}(\mathrm{PO})$ & {$[29]$} \\
5 & 1267 & FeMoC & {$[28]$} \\
6 & 1407 & Keplerate, w-m, $\mathrm{v}_{\mathrm{s}}(\mathrm{COO})$ & {$[31]$} \\
7 & 1533 & Keplerate, $\mathrm{m}, \mathrm{v}_{\mathrm{as}}(\mathrm{COO})$ & {$[31]$} \\
8 & 1612 & Keplerate, $\mathrm{m}, \delta\left(\mathrm{H}_{2} \mathrm{O}\right)$ & {$[31]$} \\
9 & 2921 & FeMoC & {$[28]$} \\
10 & 2971 & FeMoC & {$[28]$} \\
\hline
\end{tabular}

${ }^{a}$ See Fig. 3 for peak numbering
Table 2 The Raman spectra peak assignment for the synthesized product

\begin{tabular}{llll}
\hline Peak $^{\mathrm{a}}$ & Wavenumber $\left(\mathrm{cm}^{-1}\right)$ & Assignment & References \\
\hline 1 & 992 & $\mathrm{~A}_{1 \mathrm{~g}}, \mathrm{~B}_{1 \mathrm{~g}} v(\mathrm{Mo}=\mathrm{O})$ & {$[30]$} \\
2 & 855 & $\beta \mathrm{MoO}_{3}$ & {$[30]$} \\
3 & 825 & $\mathrm{Keggin}, v\left(\mathrm{O}_{\mathrm{br}}\right)$ & {$[29]$} \\
4 & 774 & $\beta \mathrm{MoO}_{3}$ & {$[30]$} \\
5 & 671 & $\mathrm{~B}_{3 \mathrm{~g}} v\left(\mathrm{OMo}_{3}\right)$ & {$[30]$} \\
6 & 340 & $\mathrm{~A}_{\mathrm{g}} \delta\left(\mathrm{OMo}_{3}\right)$ & {$[30]$} \\
7 & 284 & $\mathrm{~B}_{2 \mathrm{~g}} \delta\left(\mathrm{O}=\mathrm{Mo}_{0}\right)$ & {$[30]$} \\
8 & 240 & $\mathrm{~A}_{\mathrm{g}}, \delta\left(\mathrm{OMo}_{3}\right)$ & {$[30]$} \\
\hline
\end{tabular}

${ }^{a}$ See Fig. 4 for peak numbering

[53]. These model free approaches allow for meaningful kinetic analysis over the whole range of conversions and temperatures. In addition, isoconversional methods were chosen for their ability to analyze and predict complex multi-step processes through their evaluation of the apparent activation energy dependence on conversion without the necessity of determining the kinetic triplet (activation energy, pre-exponential factor, and reaction model) for each individual step [38].

\section{Thermogravimetric Analysis}

The TGA results of hydrogen reduction of $\mathrm{FeMoC}$ at different heating rates are shown in Fig. 5. In general the hydrogen reduction of $\mathrm{FeMoC}$ can be divided into 3 regions. In the first region below $200{ }^{\circ} \mathrm{C}$, the weight loss is attributed to the loss of $\mathrm{H}_{2} \mathrm{O}$ and ethanol constituents in agreement with the endothermic DSC profile (Fig. S1). In the second region $\left(\mathrm{X}<400{ }^{\circ} \mathrm{C}\right)$, the weight loss is attributed to the decomposition of the organic substituents as 


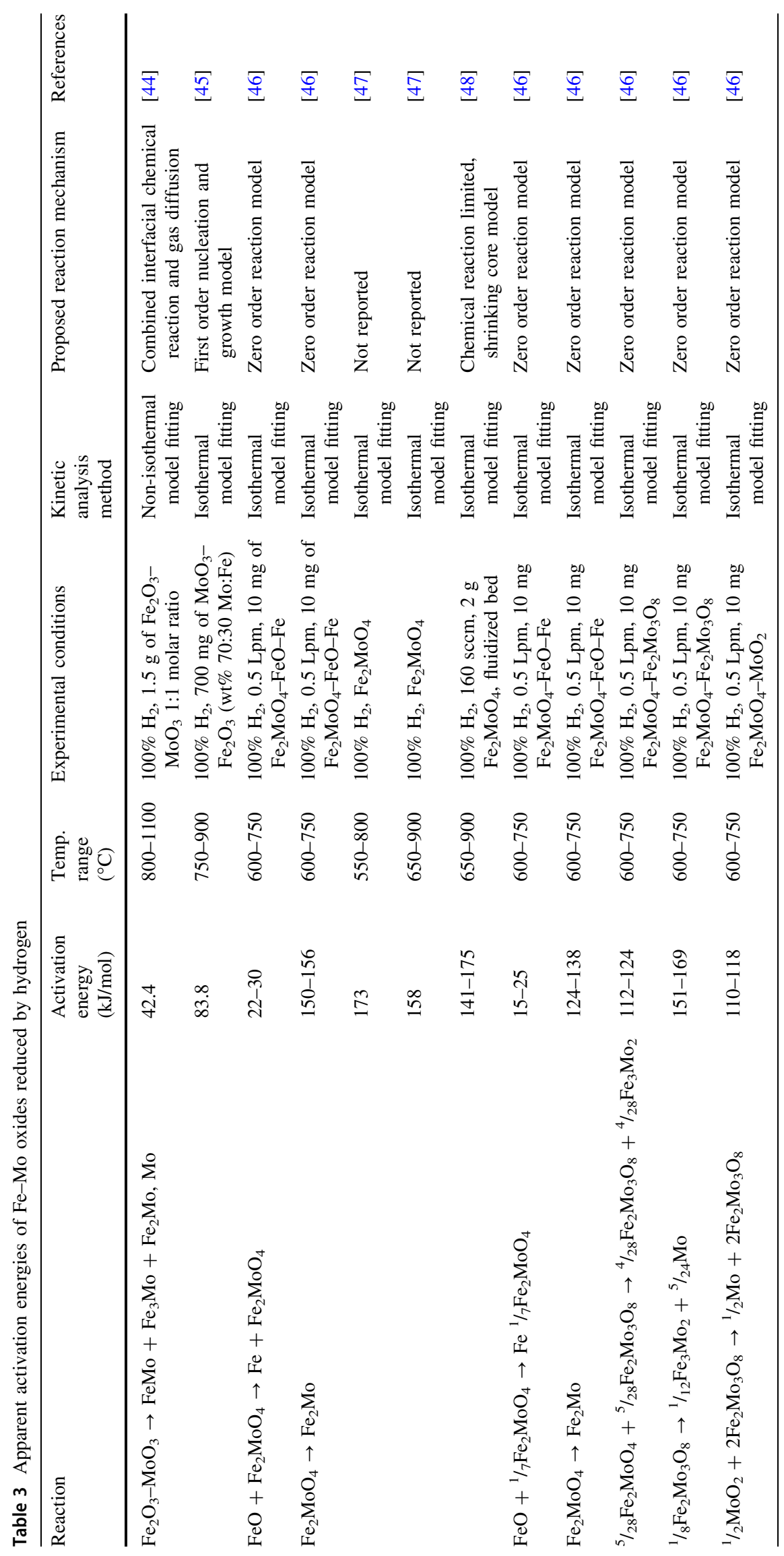


Table 4 The $f(\alpha)$ and $g(\alpha)$ functions of common solid-state reaction models

\begin{tabular}{lll}
\hline Model & $\mathrm{F}(\alpha)$ & $\mathrm{G}(\alpha)^{\mathrm{a}}=\mathrm{kt}$ \\
\hline Nucleation models & & \\
Power law (P2) & $2 \alpha^{1 / 2}$ & $\alpha^{1 / 2}$ \\
Power law (P3) & $3 \alpha^{2 / 3}$ & $\alpha^{1 / 3}$ \\
Power law (P4) & $4 \alpha^{3 / 4}$ & $\alpha^{1 / 4}$ \\
Avrami-Erofeyev (A2) & $2(1-\alpha)[-\ln (1-\alpha)]^{1 / 2}$ & {$[-\ln (1-\alpha)]^{1 / 2}$} \\
Avrami-Erofeyev (A3) & $3(1-\alpha)[-\ln (1-\alpha)]^{2 / 3}$ & {$[-\ln (1-\alpha)]^{1 / 3}$} \\
Avrami-Erofeyev (A4) & $4(1-\alpha)[-\ln (1-\alpha)]^{3 / 4}$ & {$[-\ln (1-\alpha)]^{1 / 4}$} \\
Prout-Tompkins (B1) & $\alpha(1-\alpha)$ & $\ln [\alpha /(1-\alpha)]+\mathrm{C}^{\mathrm{b}}$ \\
Geometrical contraction models & & \\
Contracting area (R2) & $2(1-\alpha)^{1 / 2}$ & $1-(1-\alpha)^{1 / 2}$ \\
Contracting volume (R3) & $3(1-\alpha)^{2 / 3}$ & $1-(1-\alpha)^{1 / 3}$ \\
Diffusion models & & \\
1-D diffusion (D1) & $1 /(2 \alpha)$ & $\alpha^{2}$ \\
2-D diffusion (D2) & $-[1 / \ln (1-\alpha)]$ & $((1-\alpha) \ln (1-\alpha))+\alpha$ \\
Ginstling-Brounshtein (D4) & $3 /\left[2\left((1-\alpha)^{-1 / 3}-1\right)\right]$ & $1-(2 / 3) \alpha-(1-\alpha)^{2 / 3}$ \\
3-D diffusion-Jander (D3) & {$\left[3(1-\alpha)^{2 / 3}\right] /\left[2\left(1-(1-\alpha)^{1 / 3}\right)\right]$} & $\left(1-(1-\alpha)^{1 / 3}\right)^{2}$ \\
Reaction-order models & & $\alpha$ \\
Zero-order (F0/R1) & 1 & $-\ln (1-\alpha)$ \\
First-order (F1) & $(1-\alpha)$ & {$[1 /(1-\alpha)]-1$} \\
Second-order (F2) & $(1-\alpha)^{2}$ & $(1 / 2)\left[(1-\alpha)^{-2}-1\right]$ \\
Third-order (F3) & $(1-\alpha)^{3}$ & \\
\hline${ }^{\mathrm{a}} g(\alpha)=\int_{0} \frac{d \alpha}{f(\alpha)}$ & & \\
${ }^{\mathrm{b}}$ C is the constant from integration & & \\
& & \\
\hline
\end{tabular}

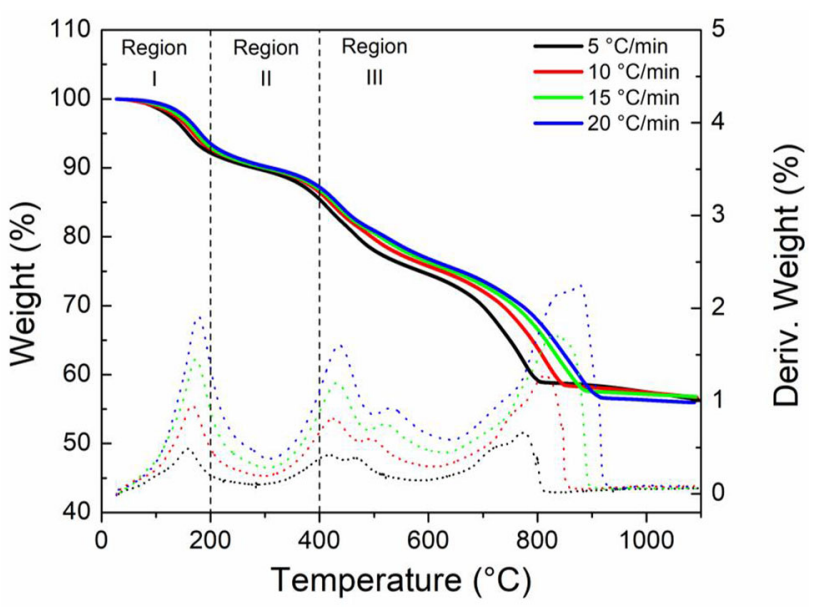

Fig. 5 The TGA (wt $\%$ ) and dTGA (Deriv. wt $\%$ ) curves of $5 \%$ hydrogen (Ar balance) reduction of $\mathrm{FeMoC}$ at different heating rates $\left(5,10,15\right.$, and $\left.20^{\circ} \mathrm{C} / \mathrm{min}\right)$ measured under a carrier gas flow rate $70 \mathrm{~mL} / \mathrm{min}$

corroborated by both the exothermic DSC profile and the measured weight loss being consistent with the loss of all water and organic substituents (exptl. $\sim 85 \%$, calc. $\sim 84 \%$ ). In the last region $\left(\mathrm{X}>\sim 400{ }^{\circ} \mathrm{C}\right)$, the resulting weight loss is attributed to the hydrogen reduction of the
$\mathrm{Fe}-\mathrm{Mo}$ oxide components as evidenced by the broad endothermic region. As can be seen in Fig. 5 the heating rate influences the TGA (wt\%) and dTGA (Deriv. wt\%) curves. Increased heating rates shift the TGA and dTGA curves to higher temperature. This temperature shift is more evident in region III when compared to regions II and I. The multiple peaks with corresponding shoulders in the dTGA profile shown in Fig. 5 are indicative of a complex multi-step kinetic process.

\section{SEM Analysis}

SEM imaging was performed on FeMoC to investigate the temperature-dependent morphological evolution of the hydrogen reduction process. Specifically, four different FeMoC samples were inspected after hydrogen reduction at $500,750,900$, and $1100{ }^{\circ} \mathrm{C}$ using a $20^{\circ} \mathrm{C} / \mathrm{min}$ ramp rate, as seen in Fig. 6. The SEM image of FeMoC reduced at $500{ }^{\circ} \mathrm{C}$ (Fig. 6a) presents irregular shaped particles with a few areas of agglomeration. At $750{ }^{\circ} \mathrm{C}$ (Fig. 6b), a significant amount of porosity and cracking can be observed. This morphology aids the penetration of the reduction gas into the structure. At $900{ }^{\circ} \mathrm{C}$ (Fig. 6c), the morphology takes on a rod-like morphology suggesting an anisotropic 

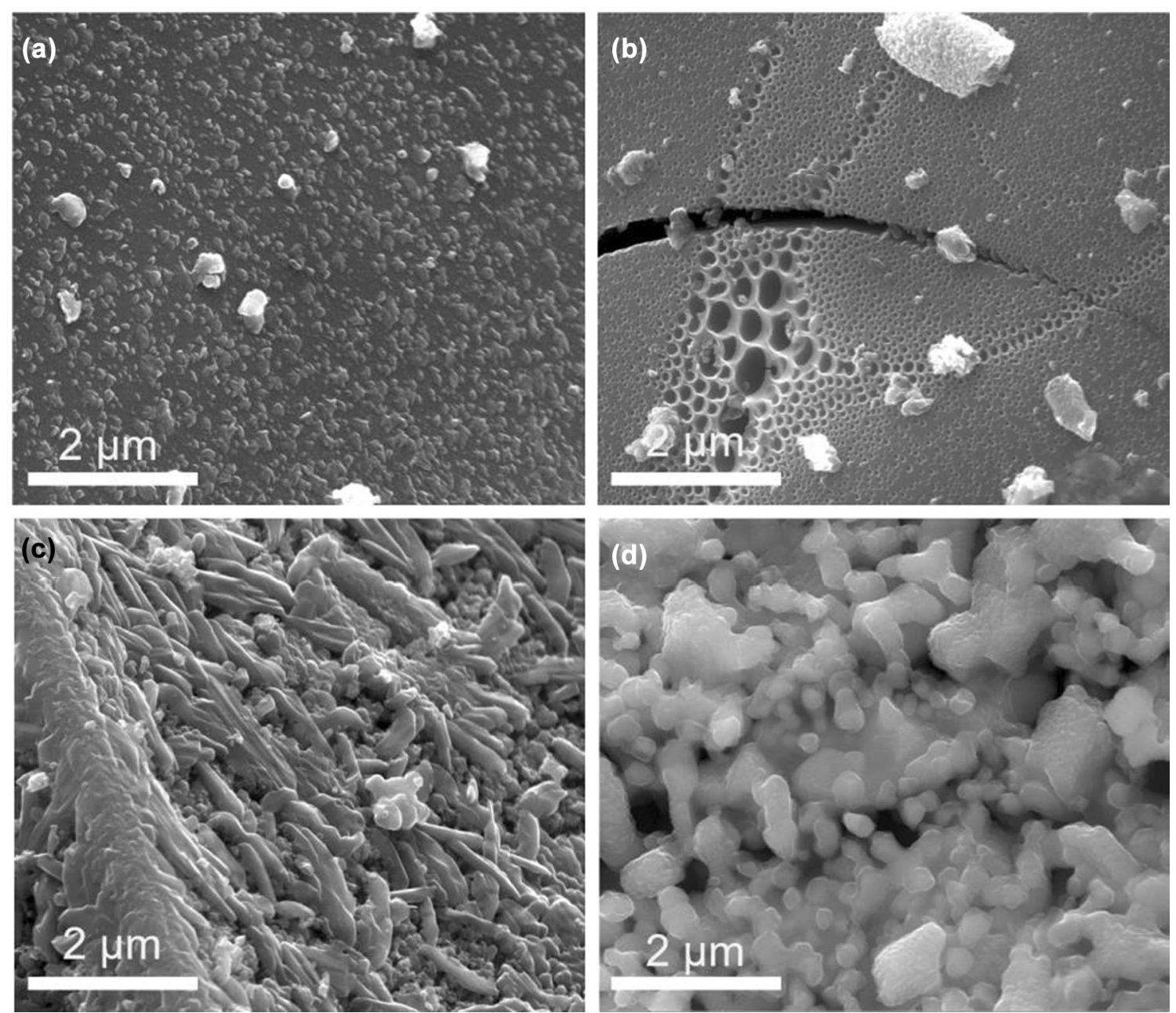

Fig. 6 The SEM images of FeMoC reduction in $5 \% \mathrm{H}_{2}$ at a 500, b 750, c 900, and d $1100{ }^{\circ} \mathrm{C}$, using a $20^{\circ} \mathrm{C} / \mathrm{min}$ heating rate

reduction pathway. At $1100{ }^{\circ} \mathrm{C}$ (Fig. 6d), the morphology appears more spherical, likely resulting from the system's tendency to achieve a lower energy state at elevated temperatures.

\section{Kinetic Analysis}

Figure 7 shows the conversion plot derived from Eq. (2) using the thermogravimetric data for the multiple heating rates $\left(5,10,15,20^{\circ} \mathrm{C} / \mathrm{min}\right)$. The conversion plot reiterates the heating rate trend of right shifting the conversion curves to higher temperature. With the conversion data the isoconversional kinetic analysis was performed. The KAS apparent activation energies were obtained from the slope of the plotted linear regression line, in accordance with Eq. (8). The computed apparent activation energies and correlation coefficients $\left(\mathrm{R}^{2}\right)$ are shown in Table 5 together with the Vyazovkin derived apparent activation energies. For a specific extent of conversion we can see a variation in apparent activation energy values obtained by the different

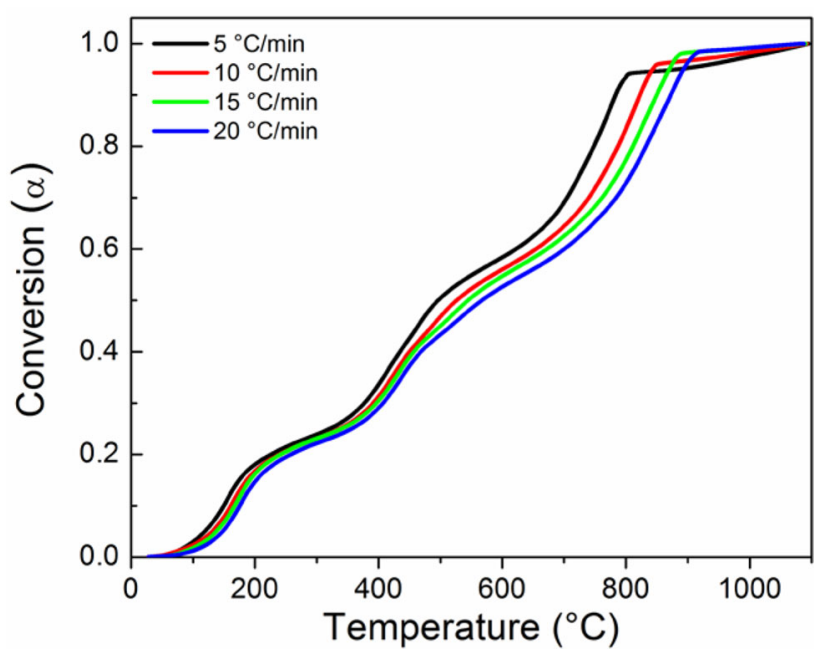

Fig. 7 The conversion, $\alpha$, of the TGA data at different heating rates $\left(5,10,15\right.$, and $\left.20^{\circ} \mathrm{C} / \mathrm{min}\right)$ derived from Eq. (2)

isoconversional methods. This variation, between the isoconversional methods, is a result of the differences in the 
Table 5 Summary of apparent activation energy and correlation coefficient values derived from all kinetic methods

\begin{tabular}{lccc}
\hline Conversion $(\alpha)$ & KAS $(\mathrm{kJ} / \mathrm{mol})^{\mathrm{a}}$ & $\mathrm{R}^{2}$ & ${\text { Vyazovkin }(\mathrm{kJ} / \mathrm{mol})^{\mathrm{b}}}^{\mathrm{b}}$ \\
\hline 0.05 & $60.8 \pm 13.3$ & 0.975 & $61.1 \pm 8.6$ \\
0.1 & $79.2 \pm 12.7$ & 0.987 & $79.5 \pm 6.4$ \\
0.15 & $83.9 \pm 19.9$ & 0.971 & $84.2 \pm 9.5$ \\
0.2 & $87.4 \pm 45.5$ & 0.876 & $87.8 \pm 20.3$ \\
0.25 & $115.1 \pm 50.1$ & 0.910 & $115.5 \pm 17.2$ \\
0.3 & $163.6 \pm 34.2$ & 0.978 & $164 \pm 8.5$ \\
0.35 & $182.6 \pm 28$ & 0.988 & $183 \pm 6.3$ \\
0.4 & $171.7 \pm 32.8$ & 0.981 & $172.1 \pm 7.7$ \\
0.45 & $116.4 \pm 19.1$ & 0.986 & $117 \pm 6.5$ \\
0.5 & $94.1 \pm 15.4$ & 0.986 & $94.8 \pm 6.2$ \\
0.55 & $92.6 \pm 22.1$ & 0.971 & $93.5 \pm 9$ \\
0.6 & $115.9 \pm 27.1$ & 0.972 & $116.8 \pm 8.9$ \\
0.65 & $136.5 \pm 24$ & 0.984 & $137.3 \pm 6.8$ \\
0.7 & $135.6 \pm 15$ & 0.994 & $136.5 \pm 4.3$ \\
0.75 & $134.4 \pm 9.2$ & 0.998 & $135.3 \pm 2.7$ \\
0.8 & $138.1 \pm 6.9$ & 0.999 & $139 \pm 1.9$ \\
0.85 & $140 \pm 8.9$ & 0.998 & $140.9 \pm 2.5$ \\
0.9 & $138.8 \pm 10.8$ & 0.997 & $139.8 \pm 3.2$ \\
$0.95^{\mathrm{c}}$ & $131.6 \pm 10.7$ & 0.998 & $132.7 \pm 0.9$ \\
\hline
\end{tabular}

${ }^{a} \mathrm{KAS} \mathrm{E}_{\alpha}$ uncertainty determined by using the traditional linear regression standard error approach with $95 \%$ confidence intervals

${ }^{\mathrm{b}}$ Vyazovkin $\mathrm{E}_{\alpha}$ uncertainty determined by the procedure proposed by Vyazovkin and Wight using 95\% confidence intervals [49]

${ }^{\mathrm{c}} \mathrm{E}_{\mathrm{a}}$ and $\mathrm{R}^{2}$ values calculated from the 10,15 , and $20{ }^{\circ} \mathrm{C} / \mathrm{min}$ heating rates. With $5{ }^{\circ} \mathrm{C} / \mathrm{min}, \mathrm{E}_{\mathrm{a}}$ values are $25.3 \pm 411\left(\mathrm{R}^{2}=0.007\right)$ and $24.54 \pm 83.4 \mathrm{~kJ} / \mathrm{mol}$, for KAS and Vyazovkin methods respectively

underlying approximations used for temperature integral, $\mathrm{p}(\mathrm{x})$, in Eq. (5). The KAS method uses the Murray and White approximation of the temperature integral yielding Eq. (11) [41].

$\mathrm{p}(\mathrm{x}) \cong \frac{\exp (-\mathrm{x})}{x^{2}}$

The more accurate Vyazovkin method uses a numerical integration approach to solve the temperature integral.

Figure 8 shows the apparent activation energy dependence on extent of conversion for the isoconversional methods used. In regions I and II $(\alpha \approx 0-0.31)$ the apparent activation energy increases with increasing extent of conversion from $\sim 60$ to $\sim 180 \mathrm{~kJ} / \mathrm{mol}$. A similar trend is seen with the thermolysis of complex organics $[54,55]$. Region III shows a more complex $\mathrm{E}_{\alpha}$ versus $\alpha$ dependency trend. For the conversion region, $\alpha=0.35-0.55$, a decline in the apparent activation energy is observed followed by an increase in apparent activation energy from $\alpha=0.55-0.65$. From $\alpha=0.65-0.95$ the

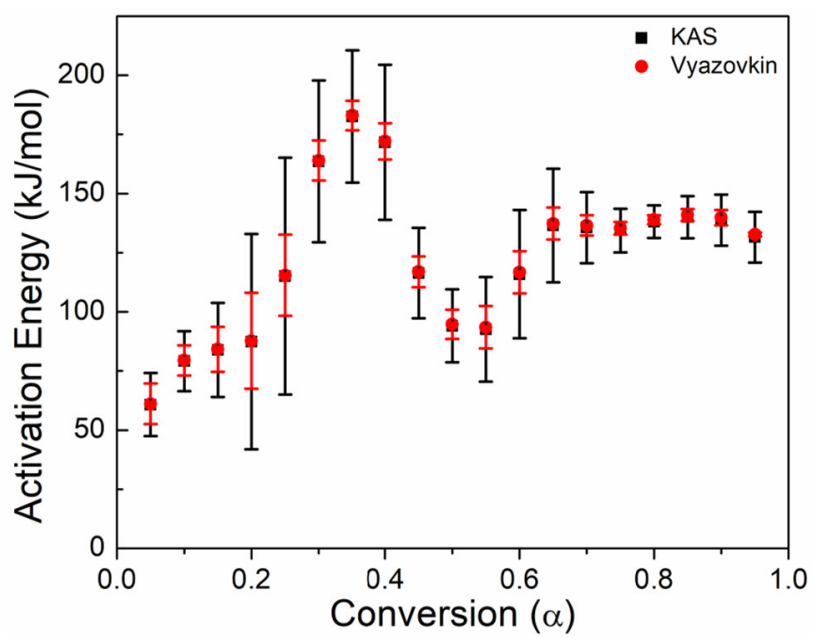

Fig. 8 The dependence of the apparent activation energy on the degree of conversion as determined by the isoconversional methods: the Kissinger-Akahira-Sunose (black), and the Vyazovkin method (red) (Color figure online)

apparent activation energy is relatively constant with an average apparent activation energy of $\sim 137 \mathrm{~kJ} / \mathrm{mol}$. This suggests that in the conversion range $0.65-0.95$, a singlestep model can adequately describe the reduction kinetics. In this regard, a model fitting procedure using $\mathrm{z}(\alpha)$ master plots was performed to find which theoretical reaction model (Table 4) best describes the conversion region of $0.65-0.95$ (Fig. S3). The contracting area theoretical model (R2) was found to best describe the experimental results in agreement with the decelerating $\alpha$ versus $t$ reaction profile derived from the isothermal experiment (Fig. S4).

Isothermal experimentation also provides a method to validate the kinetic analysis by comparing the predicted conversion simulations with the conversion curves of isothermal experiments. If the isoconversionally derived kinetic parameters used in the simulations are valid then the isothermal experiments can be satisfactorily predicted. Isothermal predictions can be performed using the $\mathrm{E}_{\alpha}$ versus $\alpha$ dependency as follows from Eq. (12) [38], where $t_{\alpha}$, is the time to reach a specific extent of conversion at the isothermal temperature, $\mathrm{T}_{0}$.

$t_{\alpha}=\frac{\int_{T_{\alpha-\Delta \alpha}}^{T_{\alpha}} \exp \left(\frac{-E_{\alpha}}{R T}\right) d T}{\beta \exp \left(\frac{-E_{\alpha}}{R T_{0}}\right)}$

Equation (12) is integrated over the temperature range ( $T_{\alpha}$ to $\mathrm{T}_{\alpha-\Delta \alpha}$ ) associated with the conversion step size $(\Delta \alpha=0.05)$ for improved accuracy. It should be noted that the real advantage of the Vyazovkin method is obtained when integrating over small temperature step sizes, as seen in Eq. (12). Figure 9 shows the experimental isothermal reduction of $\mathrm{FeMoC}$ at $850{ }^{\circ} \mathrm{C}$ with the corresponding 


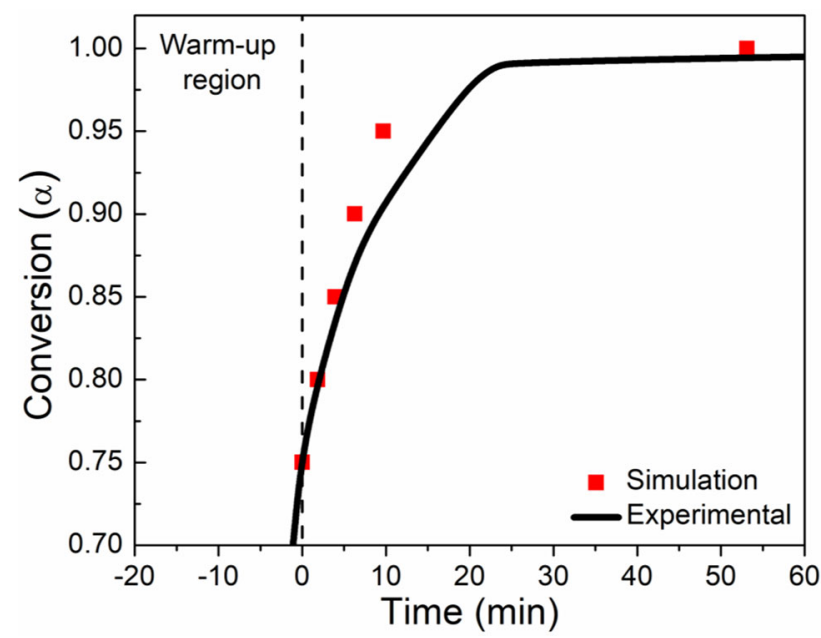

Fig. 9 The isothermal kinetic prediction plot of hydrogen reduction of $\mathrm{FeMoC}$ at $850{ }^{\circ} \mathrm{C}$. The experimental data (black) is shown with the simulated prediction points (red) (Color figure online)

kinetic prediction. The isoconversional kinetic results are validated given the satisfactory prediction.

\section{Conclusions}

Hydrogen reduction of the nanocluster FeMoC was investigated using non-isothermal TGA measurements at different heating rates $\left(5,10,15,20{ }^{\circ} \mathrm{C} / \mathrm{min}\right)$. The associated weight loss is characterized by three regions: (I) the loss of water and ethanol, (II) the decomposition of organic substituents, and (III) the reduction of Fe-Mo oxides. The apparent activation energy dependence with conversion was evaluated using model free isoconversional methods. A complex multi-step kinetic process is detected from the isoconversional analysis. In the conversion range of 0.65-0.95 the apparent activation energy was found to be relatively constant $\left(\mathrm{E}_{\mathrm{avg}}=137 \mathrm{~kJ} / \mathrm{mol}\right)$; with this conversion range being best described by the contracting area theoretical model. Isothermal experiments validate kinetic results as evidenced by the close agreement of kinetic predictions. These results provide a foundation for computationally modeling the gas-solid reduction of FeMoC and related molecular nanoclusters.

Acknowledgements Financial support for this work is provided by the Robert A. Welch Foundation (C-0002), the NSF IRISE training program at Rice University (NSF EHR-0966303), and the Welsh Government Sêr Cymru Programme.

\section{Compliance with Ethical Standards}

Conflict of interest The authors declare no conflict of interest.
Open Access This article is distributed under the terms of the Creative Commons Attribution 4.0 International License (http://creative commons.org/licenses/by/4.0/), which permits unrestricted use, distribution, and reproduction in any medium, provided you give appropriate credit to the original author(s) and the source, provide a link to the Creative Commons license, and indicate if changes were made.

\section{References}

1. Y.-J. Chen, X.-M. Gao, X.-P. Di, Q.-Y. Ouyang, P. Gao, L.-H. Qi, C.-Y. Li, and C.-L. Zhu (2013). ACS Appl. Mater. Interfaces 5, 3267.

2. J. Liang, M. Zhuo, D. Guo, Z. Chen, W. Ren, M. Zhang, and Q. Li (2016). Mater. Lett. 168, 171.

3. J. Li, L. Wang, H. Liu, J. Zhao, X. Li, H. Wei, and Y. Han (2017). J. Alloys Compd. 694, 939.

4. X. Gao, C. Li, Z. Yin, and Y. Chen (2015). RSC Adv. 5, 37703.

5. Y. Sun, X. Hu, W. Luo, J. Shu, and Y. Huang (2013). J. Mater. Chem. A 1, 4468.

6. X. Hu, W. Zhang, X. Liu, Y. Mei, and Y. Huang (2015). Chem. Soc. Rev. 44, 2376.

7. A. Pramanik, S. Maiti, and S. Mahanty (2017). Chem. Eng. J. 307, 239

8. H. Adkins and W. R. Peterson (1931). J. Am. Chem. Soc. 53, 1512.

9. C. Brookes, P. P. Wells, G. Cibin, N. Dimitratos, W. Jones, D. J. Morgan, and M. Bowker (2014). ACS Catal. 4, 243.

10. A. P. V. Soares, M. Farinha Portela, A. Kiennemann, L. Hilaire, and J. M. M. Millet (2001). Appl. Catal. Gen. 206, 221.

11. J. H. Hafner, M. J. Bronikowski, B. R. Azamian, P. Nikolaev, A. G. Rinzler, D. T. Colbert, K. A. Smith, and R. E. Smalley (1998). Chem. Phys. Lett. 296, 195.

12. Y. Li, J. Liu, Y. Wang, and Z. L. Wang (2001). Chem. Mater. 13, 1008

13. X. Wang, Q. Li, J. Xie, Z. Jin, J. Wang, Y. Li, K. Jiang, and S. Fan (2009). Nano Lett. 9, 3137.

14. L. Kang, Y. Hu, H. Zhong, J. Si, S. Zhang, Q. Zhao, J. Lin, Q. Li, Z. Zhang, L. Peng, and J. Zhang (2015). Nano Res. 8, 3694.

15. E. Mora, J. M. Pigos, F. Ding, B. I. Yakobson, and A. R. Harutyunyan (2008). J. Am. Chem. Soc. 130, 11840.

16. A. R. Harutyunyan, B. K. Pradhan, U. J. Kim, G. Chen, and P. C. Eklund (2002). Nano Lett. 2, 525.

17. S. K. Youn and H. G. Park (2013). J. Phys. Chem. C 117, 18657.

18. B. N. Wanjala, B. Fang, S. Shan, V. Petkov, P. Zhu, R. Loukrakpam, Y. Chen, J. Luo, J. Yin, L. Yang, M. Shao, and C.J. Zhong (2012). Chem. Mater. 24, 4283.

19. M. Mandal, S. Kundu, T. K. Sau, S. M. Yusuf, and T. Pal (2003). Chem. Mater. 15, 3710.

20. M. T. Reetz and W. Helbig (1994). J. Am. Chem. Soc. 116, 7401.

21. V. Abdelsayed, A. Aljarash, M. S. El-Shall, Z. A. Al Othman, and A. H. Alghamdi (2009). Chem. Mater. 21, 2825.

22. Y. Mizukoshi, T. Fujimoto, Y. Nagata, R. Oshima, and Y. Maeda (2000). J. Phys. Chem. B 104, 6028.

23. C. J. Choi, O. Tolochko, and B. K. Kim (2002). Mater. Lett. 56, 289.

24. H. J. Fecht, E. Hellstern, Z. Fu, and W. L. Johnson (1990). Metall. Trans. A 21, 2333.

25. G. L. Esquenazi and A. R. Barron, submitted for publication.

26. D. Ogrin and A. R. Barron (2007). J. Cluster Sci. 18, 113.

27. R. Colorado Jr., C. Crouse, C. N. Zeigler, and A. R. Barron (2008). Langmuir 24, 8912. 
28. R. E. Anderson, R. Colorado Jr., C. Crouse, D. Ogrin, B. Maruyama, M. J. Pender, C. L. Edwards, E. Whitsitt, V. C. Moore, D. Koveal, C. Lupu, M. P. Stewart, R. E. Smalley, J. M. Tour, and A. R. Barron (2006). Dalton Trans. 25, 3097.

29. A. Müller, S. K. Das, P. Kögerler, H. Bögge, M. Schmidtmann, A. X. Trautwein, V. Schünemann, E. Krickemeyer, and W. Preetz (2000). Angew. Chem. Int. Ed. Engl 39, 3413.

30. M. A. Camacho-López, L. Escobar-Alarcón, M. Picquart, R. Arroyo, G. Córdoba, and E. Haro-Poniatowski (2011). Opt. Mater. 33, (3), 480.

31. A. Müller, E. Krickemeyer, S. K. Das, P. Kögerler, S. Sarkar, H. Bögge, M. Schmidtmann, and S. Sarkar (2000). Angew. Chem. Int. Ed. Engl 39, 1612.

32. W. K. Jozwiak, E. Kaczmarek, T. P. Maniecki, W. Ignaczak, and W. Maniukiewicz (2007). Appl. Catal., A 326, 17.

33. H.-Y. Lin, Y.-W. Chen, and C. Li (2003). Thermochim Acta 400 , 61.

34. M. J. Tiernan, P. A. Barnes, and G. M. B. Parkes (2001). J. Phys. Chem. B 105, 220.

35. B. Hou, H. Zhang, H. Li, and Q. Zhu (2012). Chin. J. Chem. Eng. 20, 10.

36. T. Ressler, R. E. Jentoft, J. Wienold, M. M. Günter, and O. Timpe (2000). J. Phys. Chem. B 104, 6360.

37. C. D. Doyle (1961). J. Appl. Polym. Sci. 5, 285.

38. S. Vyazovkin, A. K. Burnham, J. M. Criado, L. A. PérezMaqueda, C. Popescu, and N. Sbirrazzuoli (2011). Thermochim. Acta 520, 1.

39. S. Vyazovkin and N. Sbirrazzuoli (2006). Macromol. Rapid Commun. 27, 1515.
40. H. E. Kissinger (1957). Anal. Chem. 29, 1702.

41. T. Akahira and T. Sunose (1971). Res. Rep. China Inst. Technol. Sci. Technol. 16, 22.

42. S. Vyazovkin (1997). J. Comput. Chem. 18, 393.

43. A. Joseph, C. E. S. Bernardes, A. I. Druzhinina, R. M. Varushchenko, T. Y. Nguyen, F. Emmerling, L. Yuan, V. Dupray, G. Coquerel, and M. E. M. da Piedade (2017). Cryst. Growth Des. 17, 1918.

44. M. Bahgat, M.-K. Paek, and J.-J. Pak (2009). J. Alloys Compd. 477, 445.

45. B.-S. Kim, S.-B. Kim, H.-I. Lee, and Y.-Y. Choi (2011). Mater. Trans. 52, 1288.

46. R. Morales (2003). Scand. J. Metall. 32, 263.

47. R. Morales, F. J. Tavera, R. E. Aune, and S. Seetharaman (2005). Scand. J. Metall. 34, 108.

48. R. Morales, D. Sichen, and S. Seetharaman (2003). Metall. Mater. Trans. B 34, 661.

49. S. Vyazovkin and C. A. Wight (2000). Anal. Chem. 72, 3171.

50. P. Brachi, F. Miccio, M. Miccio, and G. Ruoppolo (2015). Fuel Process. Technol. 130, 147.

51. C. K. Gupta Extractive Metallurgy of Molybdenum (CRC Press, Boca Raton, 1992), pp. 1-404.

52. S. Vyazovkin and C. A. Wight (1999). Thermochim. Acta 340, 53.

53. R. Serra, J. Sempere, and R. Nomen (1998). Thermochim. Acta 316, 37.

54. A. E. Jablonski, A. J. Lang, and S. Vyazovkin (2008). Thermochim. Acta 474, 78.

55. G. Mishra and T. Bhaskar (2014). Bioresour. Technol. 169, 614. 